\title{
Evaluation of the Early Age Married Girls Applying to Our Department
}

\author{
Bulut Kasım" ${ }^{*}$, Uysal Cem1, Korkmaz Mustafa1, Sivri Süleyman², Bozkurt İsmail1, \\ Durmaz Ubeydullah1, Tiraşçı Yaşar1, Gören Süleyman1 \\ ${ }^{1}$ Forensic Medicine Department, Dicle University, Diyarbakır, Turkey \\ ${ }^{2}$ Diyarbakır Directorate of Forensic Medicine Office, Diyarbakir, Turkey \\ Email: *drksmblt@hotmail.com
}

Received 25 July 2015; accepted 27 December 2015; published 30 December 2015

Copyright (C) 2015 by authors and Scientific Research Publishing Inc.

This work is licensed under the Creative Commons Attribution International License (CC BY). http://creativecommons.org/licenses/by/4.0/

c) (i) Open Access

\begin{abstract}
Underage marriages are going on to keep their commonness in countries such as Turkey although frequencies of them are decreasing in the world. According to the law, marriages before eighteen years old are also defined as early marriages. Being married of girls at early ages makes these children deprived from education life and their vicinity. Therefore severe psychological difficulties occur in these children. In this study, 19 girls, who were being married at early ages and psychologically examined between January $1^{\text {st }}, 2013$-April $1^{\text {st }}, 2015$ in physical and mental health committee of the Dicle University, Medical Faculty, were taken to evaluate. These 19 cases were retrospectively assessed in sociodemographic data (age, education level, and relative degrees), type of marriage, state of mind, forensic reports and files. Of 410 cases, who admitted to our mental and physical committee, $19(4.6 \%)$ were at the category of early age marriage. These 19 cases range between 13 and 17 years of age. Three of them $(15.8 \%)$ were thinking of suicide and one of them (5.3\%) attempted suicide. At least, one mental disorder was diagnosed in $8(42.1 \%)$ of the cases and the most common diagnose was acute stress disorder in four $(21.1 \%)$ cases. It has been stated that marriages at early ages are caused by economic and cultural reasons. As conclusion, being married of children at early ages is an important risk factor in social and mental health.
\end{abstract}

\section{Keywords}

Child Marriage, Mental Disorders, Forensic Medicine

\section{Introduction}

Marriage is defined as a relation which has a legal validity between an adult female and male requiring certain "Corresponding author.

How to cite this paper: Kasım, B., Cem, U., Mustafa, K., Süleyman, S., İsmail, B., Ubeydullah, D., Yaşar, T. and Süleyman, G. (2015) Evaluation of the Early Age Married Girls Applying to Our Department. Open Journal of Pediatrics, 5, 334-338. 
rights and liabilities [1] [2]. Although early age marriages decrease gradually worldwide, it is still common in underdeveloped countries or developing countries such as Turkey. United Nations and other international organizations define child marriages as violation of children and human rights. Universal declaration of human rights mentions that individuals should marry with their own free will in the lawful ages. Code of Child Welfare identifies the child as "the minor individual even she/he reaches the puberty in the early ages" [3]. Accordingly, marriages before 18 years of age are evaluated as "early marriages" [4] [5]. Turkish Civil Code states the earliest marriage age as 17 and 16 by decision of the judge for extraordinary circumstances [6]. When girls are noted to be espoused before 15 years of age, penalty is predicted for the crime of "sexual abuse of the child" for the spouse and taking part in the crime for parents of both the girl and his spouse [7]. No penalty codes are involved in our law system for early marriages. Since existing penal codes are focused on sexual abuse, some problems are faced [4].

A study conducted detected that marriage over 60 million among all existing marriages worldwide consist of minor children. These marriages include approximately 30 million in Southern Asia, 14 million in African Sahara and 6.6 million in Latin America and Caribbean. Furthermore, 50\% of the girls marry in the early ages in some regions of India [8]. Early age pregnancies which appear as a result of these marriages are defined as a serious healthcare problem in the world since 1960 [9]. In Turkey, child marriages are observed as one of the four marriages as well as one of three marriages in some regions [4]. Research of Turkish Population and Health Research (TPHR) performed on 8867 women between the ages of 20 and 49 in 2008 determined $40.3 \%$ of women married before 20 years, 22.2\% married until 18 years and 4.4\% married before 15 years. Marriages before 15 years of age which was 7.6\% in 1998 were detected as 5.0\% in 2003 and 4.4\% in 2008 in our country [10]. Despite significant decrease in the very early marriage, they still exist. Number of early marriages is predicted to increase especially in the Southeastern Anatolia region and in many other regions by asylum of the individuals running away from the civil war in Syria in particular and there is not any study conducted on this topic yet.

Early marriages before completion of biopsychosocial maturity of the girls may lead severe traumas. Children are overwhelmed by severe burden of the marriage as well as deprived of the environment and education life with their peers. These children, as a result, feel rejected, ineligible and consequently unhappy. Severe mental problems appear on these children accordingly [3] [4].

The aim of the present study was to evaluate sociodemographic characteristics of the girls who were referred our department for evaluation of physical and mental health and were below 18 years of age when they married, and also mental disorder diagnoses.

\section{Materials \& Methods}

In the present study, through request of the courts, 410 victims who were exposed to sexual assault were assessed in Dicle University Medical Faculty Hospital between January, 1st, 2013 and April, 1st, 2015. Since 19 cases meet the early marriage criteria among 410 cases, our manuscript was limited by 19 cases. Sociodemographic data (age, educational level, kinship level etc.), form of the marriage, pregnancy status, mental status of the child after the assault were evaluated retrospectively. Categorical variables were presented in number of the cases and (\%). Since no mental retardation was considered on the cases included clinically, intelligence test was not deemed necessary. This study was approved by the local Ethics Committee of Dicle Univesity, Medical School. The objective of our committee is to evaluate if mental health of the cases who were exposed to sexual assault have disrupted (post-traumatic stress disorder, acute stress reaction, incident-induced depression). Concerning courts request this evaluation from us. The case is questioned to detect this disorder. The cases voluntarily answer these questions. Therefore, this included the informed consent.

SPSS for Windows 16.0 package program was used for statistical analysis of the study. Categoric data were analyzed by ki-square test. Frequency distribution and mean values were calculated. The significance level of $95 \%(\mathrm{p}<0.05)$ was adopted in the study.

\section{Results}

Age range of marriage of 19 cases (4.6\%) included were found between 13 and 17. Most common age of our cases was 13 with 6 (31.6\%) cases. Eight (42.1\%) cases were observed as not literate, 6 (31.6\%) cases were elementary school graduate and 5 (26.3\%) cases were high school graduate. Mental retardation was not detected in any of the cases clinically. 
Before marriage, 10 (52.6\%) cases were from extended families, 8 (42.1\%) were from elementary families and 1 (5.3\%) was from broken families. After marriage, 10 (52.6\%) cases started to live in an elementary family whereas 9 (46.4\%) started to live in an extended family.

Eight (42.1\%) cases were observed to be married off to close relatives (cousin) and 11 (57.9\%) married with individuals without any kinship. No early marriage with distant relative was detected in our study.

It was detected that 8 (42.1\%) cases married with their own free will and within their parents' knowledge, 6 (31.6\%) cases married with the accused after eloping, 2 (10.5\%) cases were forced into marriage with the accused by their parents without their own free will and 2 (10.5\%) cases were forced into marriage involuntarily after being raped and 1 (5.3\%) married with the accused with her own free will after being kidnapped.

Detection form of early marriages in our study included the following; most common appearance of the event by reflection of domestic violence to judicial authorities with 6 (31.6\%) cases, 4 (21.1\%) cases were detected after delivery in the hospital, 3 (15.8\%) cases during pregnancy follow-up of the child and 3 (15.8) cases by referring to the court because of sexual intercourse and $2(10.5 \%)$ cases by referring to the court because of eloping of the child.

Girls enrolled into the study were observed with history of one and multiple pregnancy in 7 (36.8\%) cases, pregnant during the examination in 3 (15.7\%) cases and not pregnant in 9 (47.4\%) cases.

At least one mental disorder has been diagnosed in 8 (42.1\%) cases; the most common diagnosis was Acute Stress disorder by 5 (26.3\%) cases and Major depressive Disorder, Post-traumatic Stress Disorder and Anxiety have also been diagnosed. Three (15.8\%) cases were understood to have a thought of suicide and $1(5.3 \%)$ case have attempted to suicide. All of these 3 cases (100\%) with thought of suicide consisted of the cases who have married involuntarily.

The situation between mental health disorder status and kinship of the victim and the accused, the age and educational level of the victim, age difference between the victim and the accused, type of marriage formation and pregnancy status of the victim are presented in Table 1 . Situation of the kinship of the victim and accused means that the accused is cousin of the victim before marriage.

\section{Discussion}

The most common causes of early marriages were reported as economical and cultural [3] [4]. Age during the first marriage is higher in line with the higher welfare of the household. Women at the highest welfare level marry after more than three years than those at the lowest welfare level. A positive relation has been detected between educational level and mean age of marriage in a study. The differences between women who had education at least at high school level and others are noticed. Age average of marriage for women who are high school graduate and over was found 24.1; this was 3 years more than the age average of women who have not completed secondary school and 5 years more than the age average of women who have been uneducated or have not graduated from elementary school [10]. Previous studies detected that families of the girls exposed to early marriage have poor economic level and majority of these girls were uneducated or quit the school before completion of the elementary school [3] [4] [11]. In the present study, income level of the families was observed poor and $42.1 \%$ of the girls were not literate and had low educational level. Majority of the girls were observed to live in expanded families because of social and economical reasons and continued to live in expanded families after marriage. Early age marriages lead many risks and problems. The women interviewed expressed that they have perceived marriage as a game and struggled to fulfill roles and tasks expected from them [2]. Unless the financial status allows, responsibilities of the marriage almost make the children to continue on education impossible. Actions to be taken to make the girls to continue on school were determined as to provide financial support to the family, to give meal to the children whose families have a low income and to assure a job after completion of the school. This study is important to indicate prevention of early marriage for the girls [12].

Early marriage also means early pregnancy. A study conducted in our country reported that $9.6 \%$ of women between 15 and 19 years of age are married and ratio for at least one live birth was $40.7 \%$ for these women [10]. Another study determined 6.4\% of the girls between 15 and 19 years of age were married in Denizli, Turkey and $76.7 \%$ of them got pregnant. Majority of the women enrolled into the research was elementary school graduate (65.5\%); $19.5 \%$ was secondary school graduate and $12.3 \%$ were high-school graduate. [9]. Low educational level of the adolescent pregnant women and their husbands was found as a risk factor for adolescent pregnancy. As a result of risk factor research for early pregnancy in many studies, higher educational level of the partner causes a decrease in the frequency of early pregnancy [9]. Early pregnancies lead to many risks. Children who 
Table 1. Characteristics of early married girls.

\begin{tabular}{|c|c|c|c|}
\hline & MHD None & MHD Present & Total \\
\hline & n (\%) & n (\%) & n (\%) \\
\hline \multicolumn{4}{|l|}{ Kinship } \\
\hline None & $8(72.7)$ & $3(37.5)$ & $11(57.9)$ \\
\hline Present & $3(27.3)$ & $5(62.5)$ & $8(42.1)$ \\
\hline \multicolumn{4}{|l|}{ Age } \\
\hline 13 & $4(36.4)$ & $2(25)$ & $6(31.6)$ \\
\hline 14 & $1(9.1)$ & $3(37.5)$ & $4(21.1)$ \\
\hline 15 & $3(27.3)$ & $1(12.5)$ & $4(21.1)$ \\
\hline 16 & $2(18.2)$ & $2(25)$ & $4(21.1)$ \\
\hline 17 & $1(9.1)$ & $0(0)$ & $1(5.3)$ \\
\hline \multicolumn{4}{|l|}{ Educational Level of the Victim } \\
\hline Not literate & $6(54.5)$ & $2(25)$ & $8(42.1)$ \\
\hline Primary education & $1(9.1)$ & $5(62.5)$ & $6(31.6)$ \\
\hline High school & $4(36.4)$ & $1(12.5)$ & $5(26.3)$ \\
\hline \multicolumn{4}{|l|}{ Age Difference } \\
\hline Accused is younger than the victim & $1(9.1)$ & $1(12.5)$ & $2(10.5)$ \\
\hline Accused is $0-5$ years older & $4(36.4)$ & $4(50.0)$ & $8(42.1)$ \\
\hline Accused is 6 - 10 years older & $5(45.5)$ & $1(12.5)$ & $6(31.6)$ \\
\hline Accused is 11 years and more older & $1(9.1)$ & $2(25.0)$ & $3(15.8)$ \\
\hline \multicolumn{4}{|l|}{ Type of Marriage Formation } \\
\hline Married voluntarily & $8(72.7)$ & $0(0)$ & $8(42.1)$ \\
\hline Married involuntarily & $0(0)$ & $2(25.0)$ & $2(10.5)$ \\
\hline Eloped voluntarily & $3(27.3)$ & $3(37.5)$ & $6(31.6)$ \\
\hline Forced to marriage by kidnapping & $0(0)$ & $1(12.5)$ & $1(5.3)$ \\
\hline Married after rape & $0(0)$ & $2(25.0)$ & $2(10.5)$ \\
\hline \multicolumn{4}{|l|}{ Pregnancy } \\
\hline None & $4(36.4)$ & $5(62.5)$ & $9(47.4)$ \\
\hline Present & 7 (63.6) & $3(37.5)$ & $10(52.6)$ \\
\hline Total & $11(57.9)$ & $8(42.1)$ & $19(100)$ \\
\hline
\end{tabular}

MHD: Mental Health disorder.

get pregnant before 18 years of age have a risk of premature birth or low birth weight babies by a rate of 35\% $55 \%$ when compared with those who get pregnant after 19 years of age. Death rate of the infants of mothers who are below 18 years is $60 \%$ more [3]. People believe that early marriage of their girls protects them from HIV/ AIDS disease. However, studies presented marriages before 20 years of age are risk factor for HIV infection. In Kenya, married girls are more likely to be infected with HIV when compared to singles by 50\%. They are infected by their husbands. Because, girls have frequent and unprotected sexual intercourse with their husbands to get pregnant as soon as possible and prove that they are fertile. Pregnant women in endemic malaria regions have a higher risk for infection. The highest risk is observed during the first pregnancy. Pregnancy is not a sole risk factor for malaria; however, incidence of malaria was found more in pregnant women below 19 years when compared with those older than 19 years of age [3]. Unintended pregnancies are observed more in early age marriages [4] [13]. In the present study, 52.6\% of the cases were detected pregnant or previously pregnant.

In a study, mental disorder was detected in $45.8 \%$ of the cases as a result of mental evaluation of the girls who had early marriage [4]. Similarly, at least one mental disorder was observed in $42.1 \%$ of these children in the present study. Our study detected that the victim had higher mental disorder rate especially in involuntary mar- 
riage of the victim.

Studies conducted found that suicidal ideation and attempt significantly increases in the cases who had early marriage [4]. In our research, suicidal ideation and attempt was observed higher in the children who had involuntary marriage in particular.

Outcomes indicate that these children who were exposed to early marriage have a significant risk for social and mental disorder. In a study, it is reported that physical and emotional violence/abuse in addition to sexual abuse, to undertake responsibilities such as home, family and children, to separate from the family, to have conflicts with the spouse's family, to live in a large family after marriage, to be forced for marriage develop mental disorders more. Therefore, consideration of sexual assault only would be deficient for the early age marriage cases; all factors that are considered to affect the child's mental health should be discussed together [4].

\section{Conclusion}

We concluded that social, educational and legal solutions to prevent early marriages should be sought; girls and their families should be trained accordingly and mental therapies of the victim girls should be performed rigorously.

\section{References}

[1] Bozkurt, V. (2004) Sociology in the Changing World. Alfa Publishing, Istanbul.

[2] Çoban, A.İ. (2009) Adolescent Marriages. Family and Community Education Culture and Research Journal, 16, 3750 .

[3] Nour, N.M. (2009) Child Marriage. A Silent Health and Human Rights Issue. Reviews in Obstetrics Gynecology, 2, 51-56.

[4] Soylu, N. and Ayaz, M. (2013) Sociodemographic Characteristics and Psychiatric Evaluation of Girls Who Were Married at Younger Age and Referred for Criminal Evaluation. Anatolian Journal of Psychiatry, 14, 136-144. http://dx.doi.org/10.5455/apd.36694

[5] Child Protection Code (2005) T.R. Official Gazette, 15, 5395. http://www.resmigazete.gov.tr/eskiler/2005/07/20050715-1.htm

[6] Turkish Civil Code. Code: 4721. (2001) T.R. Official Gazette, 8, 24607. http://www.resmigazete.gov.tr/eskiler/2001/12/20011208.htm\#1

[7] Resolution of Penal Department no. 2007/1609K of Supreme Court Dated 28.02.2007 https://www.tbmm.gov.tr/komisyon/kefe/docs/komisyon_rapor.pdf

[8] Vasanth, C., Ilayaraja, B.S. and Ramya, S. (2015) Assessing Parents Awareness on Health Impacts of Early Marriage: A Study in Selected Villages of Moradabad. International Journal of Basic Medicine and Clinical Research, 2, 98-102.

[9] Özşahin, A., Zencir, M., Gökçe, B. and Acimis, N. (2006) Adolescent Pregnancy in West Turkey. Cross Sectional Survey of Married Adolescents. Saudi Medical Journal, 27, 1177-1182.

[10] Turkish Population and Health Research. Hacettepe University, Institute for Population Survey, General Directorate of Mother and Child Care and Family Planning, Secreteriat of the State Planning Organization and TUBITAK, Ankara, Turkey, 2008.

[11] Noah, G. (2007) Uganda: Early Marriage as a form of Sexual Violence. Forced Migration Review, 27, 51-55. http://www.fmreview.org/en/FMRpdfs/FMR27/full.pdf

[12] Mathur, S., Greene, M. and Malhotra, A. (2003) Too Young to Wed: Thelives, Rights and Health of Young Married Girls. International Center for Research on Women, Washington DC, 1-5.

[13] Santhya, K.G. (2011) Early Marriage and Sexual and Reproductive Health Vulnerabilities of Young Women: A Synthesisof Recent Evidence from Developing Countries. Current Opinion in Obstetrics and Gynecology, 23, 334-339. http://dx.doi.org/10.1097/GCO.0b013e32834a93d2 